\title{
DIAGNOSTIC AND PREDICTIVE VALUE OF RIGHT HEART CATHETERIZATION-DERIVED MEASUREMENTS IN PULMONARY HYPERTENSION
}

DOI: $10.36740 /$ WLek202103130

\author{
Karolina Barańska-Pawełczak', Celina Wojciechowska², Wojciech Jacheć ${ }^{2}$ \\ 'DEPARTMENT OF CARDIOLOGY, SPECIALISTIC HOSPITAL IN ZABRZE, ZABRZE, POLAND \\ 2SECOND DEPARTMENT OF CARDIOLOGY, SCHOOL OF MEDICINE WITH THE DIVISION OF DENTISTRY IN ZABRZE, MEDICAL UNIVERSITY OF SILESIA, \\ KATOWICE, POLAND
}

\begin{abstract}
Right heart catheterization is a unique tool not only in the diagnosis but also in the management of patients with a wide range of cardiovascular diseases. The technique dates back to the $18^{\text {th }}$ century, but the biggest advances were made in the $20^{\text {th }}$ century. This review focuses on pulmonary hypertension for which right heart catheterization remains the diagnostic gold standard. Right heart catheterization-derived parameters help classify pulmonary hypertension into several subgroups, assess risk of adverse events or mortality and make therapeutic decisions. According to the European Society of Cardiology guidelines pulmonary hypertension (PH) is defined as an increase in mean pulmonary artery pressure (PAPm) $>25 \mathrm{mmHg}$, whereas a distinction between pre- and post-capillary PH is made based on levels of pulmonary artery wedge pressure (PAWP). Moreover, right atrial pressure (RAP), cardiac index $(\mathrm{Cl})$ and mixed venous oxygen saturation $\left(\mathrm{SvO}_{2}\right)$ are the only parameters recommended to assess prognosis and only in patients with pulmonary arterial hypertension (PAH). Patients with RAP $>14 \mathrm{mmHg}, \mathrm{Cl}<2.0 \mathrm{l} / \mathrm{min} / \mathrm{m}^{2}$ and $\mathrm{Sv}_{2}<60 \%$ are at high ( $>10 \%$ ) risk of death within the next year. The purpose of this paper is to show that RHC-derived parameters can be used on a considerably larger scale than currently recommended. Several prognostic parameters, with specific thresholds have been identified for each subtype of pulmonary hypertension and can be helpful in everyday practice for treatment of PH.
\end{abstract}

KEY WORDS: pulmonary hypertension, right heart catheterization, pulmonary artery hypertension

Wiad Lek. 2021;74(3 p.l):546-553

\section{INTRODUCTION}

Right heart catheterization (RHC) is a medical procedure that has been used for decades to evaluate heart function and to diagnose a wide spectrum of cardiovascular diseases. The history of catheterization began in 1711 when Stephen Hale performed the first catheterization of equine vessels using brass pipes to measure blood pressure and cardiac output. In 1844, physiologist Claude Bernard was the first to catheterize right and left ventricle in a horse using glass tubes. The $20^{\text {th }}$ century witnessed rapid developments in cardiac catheterization beginning with self-cannulation using a urethral catheter by dr. Forssmann in 1929, through advances in the procedure made by dr. André Cournand and dr. Dickinson Richards in 1940, followed by the Nobel Prize in 1956 for dr. Cournand, dr. Richards and dr. Werner, and finally the development of a 'Swan-Ganz' catheter in 1970 by Jeremy Swan and William Ganz, from Cedars-Sinai Medical Center [1].

For decades RHC has been used in many clinical situations, to monitor patients in the Intensive Care Units and assess cardiac output, to perform pulmonary angiography, to detect and evaluate shunts between the systemic and pulmonary circulation, to diagnose pulmonary hypertension and examine patients before cardiac transplantation, to assess the heart function in valvular or congenital diseases, to distinguish between restrictive cardiomyopathy and constrictive pericarditis or to provide an access for endomyocardial biopsy heart defect closure (since 1976) or balloon pulmonary angioplasty [2]. RHC is part of a mandatory and comprehensive evaluation of $\mathrm{PH}$ patients. The RHC findings are used not only to confirm the diagnosis but also to predict survival or mortality in patients with specific PH subtypes.

\section{THE AIM}

The aim of this paper is to establish the cut-off values of several pulmonary hemodynamic parameters which can be useful in everyday practice. According to the current guidelines only some RHC parameters (RAP, CI and $\mathrm{SvO}_{2}$ ) are relevant for estimating prognosis and only in $\mathrm{PAH}$ patients. $\mathrm{PAH}$ is a relatively rare disease, according to the Polish Registry of $\mathrm{PH}$ the average prevalence is 30.8 per million adults [3]. This entails difficulties in selecting a sufficiently large sample size to perform a reliable statistical analysis, nevertheless numerous studies have demonstrated the prognostic value of various RHC-derived parameters, not only in $\mathrm{PAH}$, but also in other $\mathrm{PH}$ subgroups. Patients with 


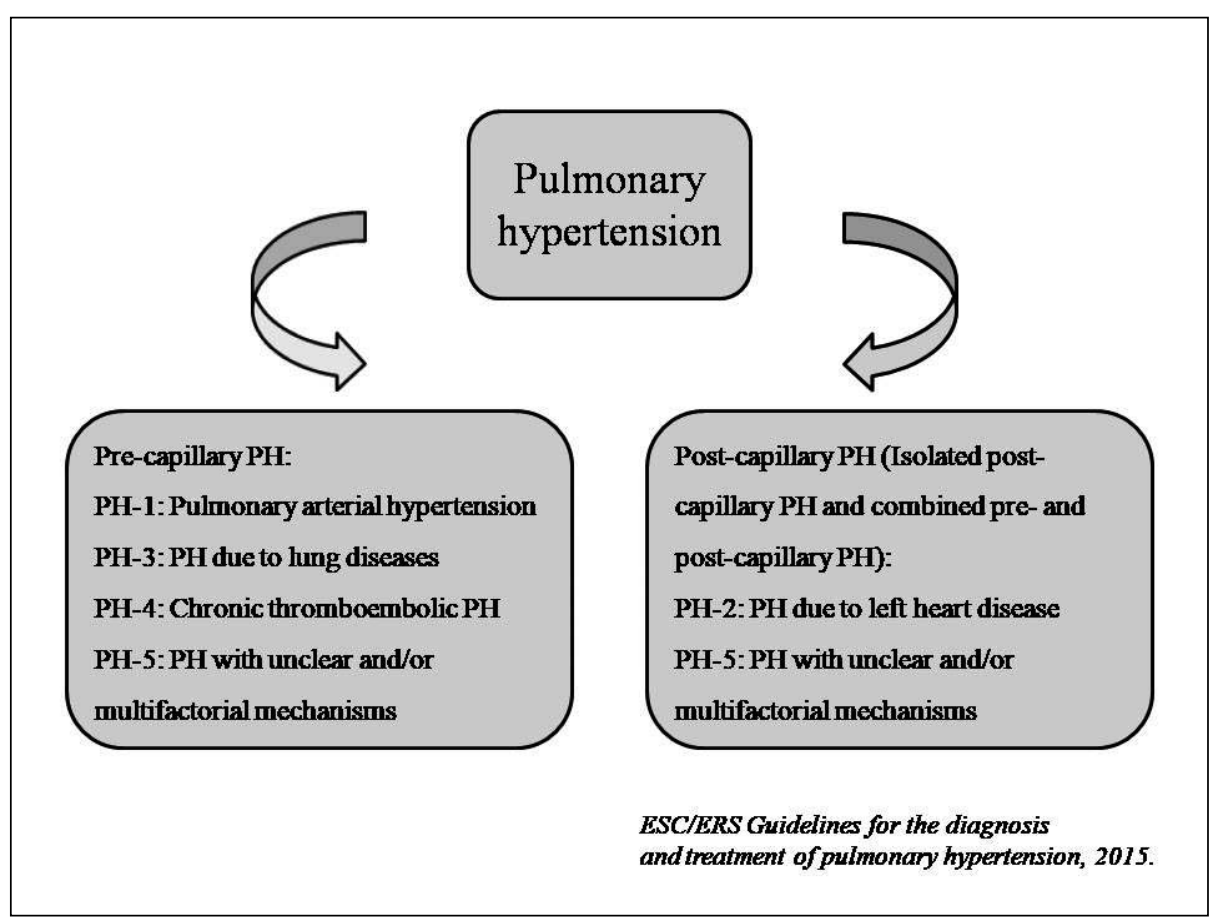

Fig. 1. Haemodynamic classification of pulmonary hypertension.
$\mathrm{PH}$ are a heterogeneous group of individuals, and although the current guidelines are quite narrowly applicable to RHC for prognosis, in our opinion the data presented below will show that RHC is essential for therapeutic decision-making and provides important prognostic information for each patient with $\mathrm{PH}$.

\section{REVIEW AND DISCUSSION}

RHC remains the gold standard in the diagnosis of pulmonary hypertension (PH), which is defined as an increase in mean pulmonary artery pressure (PAPm) $\geq 25 \mathrm{mmHg}$, and further classified into pre-capillary and post-capillary $\mathrm{PH}$ (with two subgroups: isolated post-capillary $\mathrm{PH}$ and combined post-capillary and pre-capillary PH) (Fig. 1, Table 1) [4].

RHC is usually performed through puncture of the subclavian or jugular vein under local anaesthetic. Optimally, a balloon-tipped catheter is inserted under fluoroscopic guidance through a central vein, right atrium and right ventricle to the pulmonary artery.

It is recommended to measure several hemodynamic parameters during RHC i.e. right atrial pressure (RAP), right ventricular pressure (RVP), pulmonary artery pressure (PAP), pulmonary artery wedge pressure (PAWP) and cardiac output $(\mathrm{CO})$. The measurements are then used to calculate cardiac index $(\mathrm{CI})$, diastolic pressure gradient (DPG), transpulmonary pressure gradient (TPG) or pulmonary vascular resistance (PVR) (Table 2). In addition, blood is drawn from intracardiac chambers, great vessels and pulmonary artery to detect and quantify shunts between the systemic and pulmonary circulation, to measure mixed venous oxygen saturation $\left(\mathrm{SvO}_{2}\right)$ and to calculate cardiac output using the Fick method [5].

During RHC, when the diagnosis of pulmonaryhypertension is confirmed, pulmonary vasoreactivity (vasodilator) testing should be performed for Group $1 \mathrm{PH}$ and Group $2 \mathrm{PH}$, to identify patients with a reversible form of $\mathrm{PH}$. Current guidelines recognize the use of four medications for assessment of pulmonary vasoreactivity, i.e. inhaled nitric oxide, inhaled iloprost or epoprostenol and intravenous adenosine (Table 3). In patients with pulmonary arterial hypertension ( $\mathrm{PAH}, \mathrm{PH}-1)$, a positive acute response (responders) is defined as a reduction of the PAPm $\geq 10$ $\mathrm{mmHg}$ to reach an absolute value of PAPm $\leq 40 \mathrm{mmHg}$ with an increased or unchanged CO [4]. A decrease of TPG below 15 $\mathrm{mmHg}$, during vasoreactivity testing with sodium nitroprusside or nitric oxide, is mandatory for $\mathrm{PH}-2$ patients with severe heart failure to be eligible for a heart transplant [6].

The current cut-off value of PAPm for a diagnosis of $\mathrm{PH}$ was established in 1973, but available data suggests that normal resting PAPm is $14.0 \pm 3.3 \mathrm{mmHg}$, therefore, new definitions of $\mathrm{PH}$ and $\mathrm{PH}$ in left heart disease (LHD) were proposed during the 6th World Symposium on Pulmonary Hypertension in Nice in 2018 (Table 4) [7]

Regarding the new $\mathrm{PH}$ definition evidence supporting its usefulness has been available in the literature for years. Elevated PAPm $\geq 20 \mathrm{mmHg}$ is associated with a significantly worse prognosis in patients with connective tissue disease (log-rank test $\mathrm{p}=0.005$ ) [8] and idiopathic pulmonary fibrosis (IPF) $(\log$-rank test $\mathrm{p}=0.001)$, compared with PAPm $<20 \mathrm{mmHg}$ [9]. Patients with PAPm $=19-24 \mathrm{mmHg}$ show a $23 \%$ (95\% CI [12-36\%], $\mathrm{P}<0.0001)$ and a $7 \%$ (95\% CI [1-12\%], P = 0.0149) increase of the adjusted hazard for mortality and hospitalization, respectively, compared to patients with PAPm $\leq 18 \mathrm{mmHg}$ [10].

\section{PULMONARY ARTERIAL HYPERTENSION (PH-1)}

According to the current $\mathrm{PH}$ guidelines the RHC-derived measurements are one of the variables used to estimate 1-year mortality in patients with PAH. RAP, CI and $\mathrm{SvO}_{2}$ 


$$
\begin{aligned}
& \mathbf{P a}=\frac{\text { SV }}{\text { PP }} \\
& \begin{array}{l}
\mathrm{PCa}(\mathrm{PAC})=\text { pulmonary vascular compliance } \\
\text { (pulmonary arterial capacitance ) }
\end{array} \\
& \begin{array}{l}
\mathrm{SV}=\text { stroke volume } \\
\mathrm{PP}=\text { pulse pressure }
\end{array}
\end{aligned}
$$

Fig. 2. Formula of the pulmonary vascular compliance.

are used to classify patients into one of the three groups according to mortality risk: low risk $<5 \%$ ( $\mathrm{RAP}<8 \mathrm{mmHg}$; $\mathrm{CI} \geq 2.5 \mathrm{l} / \mathrm{min} / \mathrm{m}^{2} ; \mathrm{SvO}_{2}>65 \%$ ), intermediate risk $5-10 \%$ (RAP 8 -14 mmHg; CI $2.0-2.41 / \mathrm{min} / \mathrm{m}^{2} ; \mathrm{SvO}_{2} 60-65 \%$ ) and high risk $>10 \%$ (RAP $>14 \mathrm{mmHg}$; $\mathrm{CI}<2.0 \mathrm{l} / \mathrm{min} /$ $\mathrm{m}^{2} ; \mathrm{SvO}_{2}<60 \%$ ) [4]. The French PAH registry shows that the initially measured hemodynamic parameters have no prognostic value, but RAP and SVI measured in patients receiving treatment (PDE-5 I, ERB, prostanoids) are predictive of poor prognosis. The risk of death or lung transplantation increases by $5 \%$ per each $1 \mathrm{mmHg}$ of RAP increase $(\mathrm{HR}=1.05 ; 95 \%$ confidence interval: $1.02-1.09$; $\mathrm{p}<0.001)$ and by $28 \%$ per each $10 \mathrm{mml} / \mathrm{m}^{2}$ of SVI decrease ( $\mathrm{HR}=1.28$; 95\% confidence interval: $1.11-1.49 ; \mathrm{p}<0.001)$. The optimal cut-off value is $9 \mathrm{~mm} \mathrm{Hg}$ for RAP (AUC $=0.62$; $95 \%$ confidence interval: $0.57-0.67 ; \mathrm{p}<0.01)$ and $38 \mathrm{ml} / \mathrm{m}^{2}$ for SVI (AUC $=0.68$; 95\% confidence interval: $0.64-0.72$; $\mathrm{p}<0.01)$. It is noteworthy that this negative impact of low SVI is seen even among those considered to be at lower risk (e.g. low NYHA class or $\mathrm{CI} \geq 2.5 \mathrm{l} / \mathrm{min} / \mathrm{m}^{2}$ ) [11]. In 2007, a study carried out in a small group of patients (64 vs. 981 patients) demonstrated that SVI $\leq 25 \mathrm{ml} / \mathrm{m}^{2}$ was a negative prognostic factor (log-rank test, $\mathrm{p}=0.010$ ) [12]. Another parameter which is significantly associated with poor outcomes is increasing DPG (Hazard ratio [HR] 1.29 per $10 \mathrm{mmHg}$ increase) [13].

In the REVEAL registry PVR was included as one of the risk factors in patients with PAH. PVR $<5$ Wood units (WU) was associated with better survival outcomes. Previously diagnosed patients with a PVR $<5$ WU had a 5 -year survival of $73.9 \% \pm 2.3 \%$, compared with $66.0 \% \pm$ $1.8 \%$ in patients with a PVR of 5 to 10 WU. Newly diagnosed patients with a PVR $<5 \mathrm{WU}$ had a 5 -year survival of $70.1 \% \pm 4.9 \%$, compared with $57.3 \% \pm 3.2 \%$ in patients with a PVR of 5 to $10 \mathrm{WU}$ [14]. The REVEAL Registry Risk Score Calculator has been developed to predict 1-year survival in patients newly diagnosed with PAH. The risk calculator is based on 15 variables, including echocardiographic findings, blood test results, clinical characteristics and classification, as well as such RHC-derived parameters as RAPm $>20 \mathrm{mmHg}$ and PVR $>32 \mathrm{WU}$ [15].

In patients with systemic sclerosis-related pulmonary arterial hypertension (SSc-PAH) several hemodynamic measurements are also predictors of increased mortality. A

\section{$100 \times$ (mPpa - Poccl) $\operatorname{Rup}=$ (mPpa -Ppao) \\ Ppao $=$ pulmonary artery occluded pressure, $\mathrm{mPpa}=$ mean pulmonary artery pressure, Poccl $=$ occlusion pressure}

study by Mukherjee et al. demonstrated that raised RAPm, raised PAPm and low CI were related to survival. The Cox multivariate regression analysis revealed that RAPm was the strongest independent factor for a poor outcome, with hazard ratio 20.7 and a p value of 0.0001 . As there was a relative correlation between RAPm, PAPm and CI, the latter two values could not be considered as independent predictors [16]. In addition, data from the REVEAL study showed that RAPm $>20 \mathrm{~mm} \mathrm{Hg}$ and PVR $>32 \mathrm{WU}$ were predictors of mortality in the SSc-PAH group [17]. Campo et al. proved that PVR $>7.2 \mathrm{WU}(\mathrm{HR}=3.13,95 \%$ confidence interval: $1.50-6.52 ; \mathrm{p}<0.01), \mathrm{SVI}<30 \mathrm{ml}(\mathrm{HR}=2.34,95 \%$ confidence interval: $1.11-4.96 ; \mathrm{p}=0.03)$ and $\mathrm{PCa}<1.25 \mathrm{ml} / \mathrm{mm} \mathrm{Hg}$ $(\mathrm{HR}=3.06,95 \%$ confidence interval: $1.41-6.65 ; \mathrm{p}<0.01)$ were strong predictors of mortality [18].

Patient selection for liver transplantation due to portopulmonary hypertension (PP-PH) requires careful hemodynamic assessment. Studies in patients with $\mathrm{PP}-\mathrm{PH}$ at Mayo Clinic provided the following results: PAPm $>50$ mmHg was associated with $100 \%$ cardiopulmonary mortality, whereas values of PAPm 35-50 mmHg and PVR > 250 dynes $\cdot \mathrm{s} \cdot \mathrm{cm}^{2}$ were linked to the mortality rate around $50 \%$. No cardiopulmonary mortality was reported in patients with PAPm $<35 \mathrm{mmHg}$ or TPG $<15 \mathrm{mmHg}$ [19].

Investigators are still searching for new RHC-derived parameters. One of them is pulmonary vascular compliance $(\mathrm{PCa})$, defined as SV divided by pulse pressure - the difference between systolic pulmonary artery pressure and diastolic pulmonary artery pressure (PAPs - PAPd), which describes elastic properties of the pulmonary arterial system (Fig. 2). In adult patients with PAH-related congenital heart disease, the Kaplan-Meier survival curves show that $\mathrm{PCa}<1.04 \mathrm{ml} / \mathrm{mmHg}$ is a risk factor for mortality (Log rank: $\mathrm{P}<0.001)$. ROC curve analysis for $\mathrm{PCa}=1.04 \mathrm{ml} /$ mmHg shows $87 \%$ sensitivity and $64 \%$ specificity (AUC $=$ $0.746,95 \%$ confidence interval: $0.657-0.836, \mathrm{P}<0.001$ ) [20]. Also in patients with idiopathic PAH (IPAH), PCa has been recognized as an indicator of mortality in univariate analysis $(\mathrm{HR}=17.0 \mathrm{per} \mathrm{ml} / \mathrm{mmHg}$ decrease; $95 \%$ confidence interval: $13.0-22.0 ; \mathrm{p}<0.0001$ ). Patients with $\mathrm{PCa}=0.40$ $0.81 \mathrm{ml} / \mathrm{mm} \mathrm{Hg}$ have a $61 \%$ 4-year mortality [21].

Surgical correction of congenital heart disease causing Eisenmenger syndrome is considered useful in patients with $\mathrm{PVRi}<4 \mathrm{WU} \cdot \mathrm{m}^{2}$ and PVR $<2.3 \mathrm{WU}$. Surgery is not the 


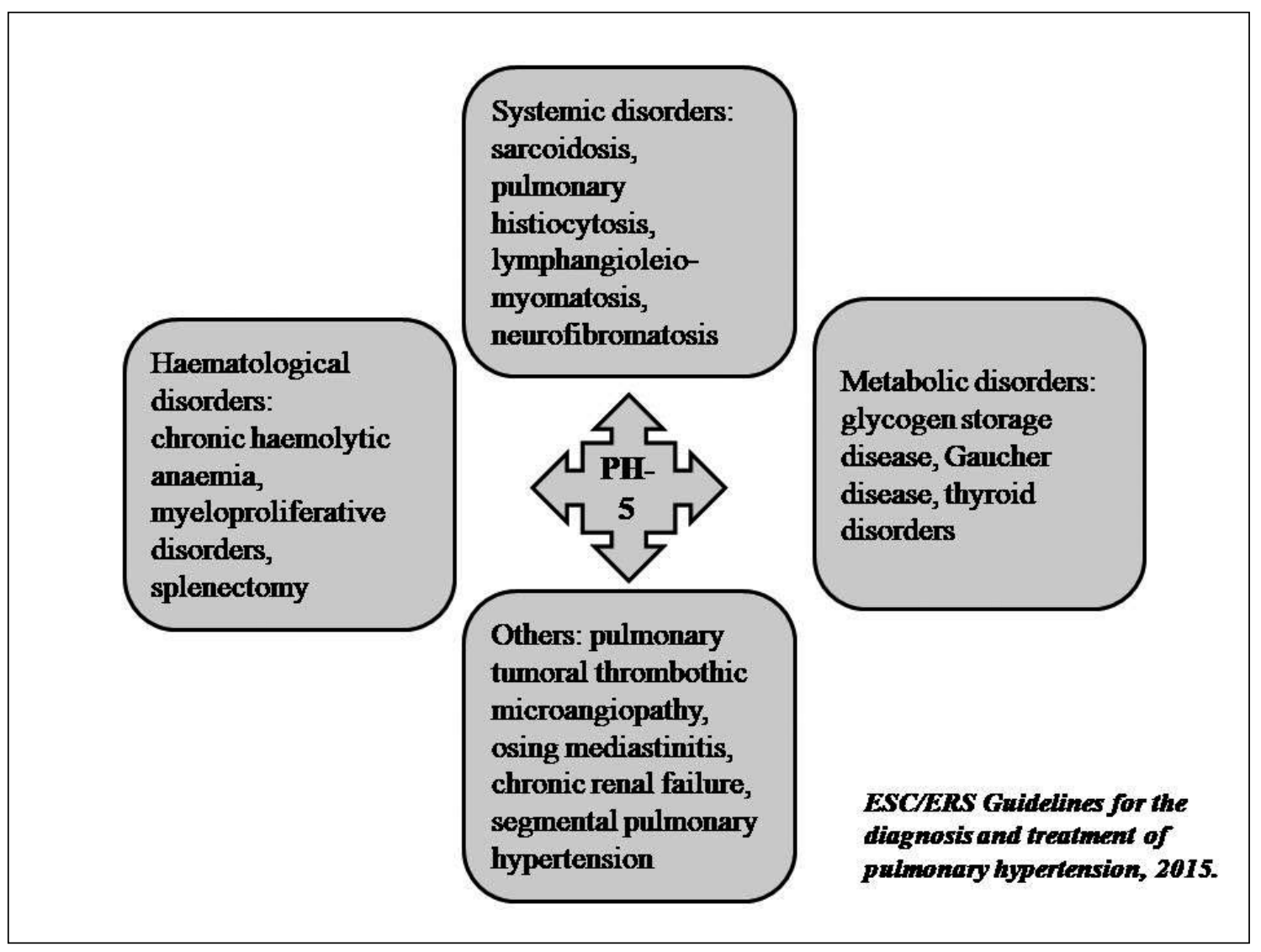

Fig. 4. Clinical classification of the group 5 pulmonary hypertension.

best option in subjects with PVRi $>8$ WU.m ${ }^{2}$ and PVR $>$ 4.6 WU. Patients with an intermediate PVRi of 4-8 WU.m ${ }^{2}$ and PVR of 2.3-4.6 WU require individualized approach [4]. In univariate analysis, SVi $(\mathrm{HR}=1.058 ; 95 \%$ confidence interval: $1.02-1.10 ; \mathrm{p}=0.002)$, PVRi $(\mathrm{HR}=1.024$; 95\% confidence interval: $1.00-1.05 ; \mathrm{p}=0.01$ ) and $\triangle \mathrm{PVRi}$ after vasoreactivity testing with intravenous epoprostenol $(\mathrm{HR}=0.972 ; 95 \%$ confidence interval: $0.95-0.99 ; \mathrm{p}=0.02)$ were found to be significant predictors of poor outcomes in patients with PAH associated with congenital heart disease and Eisenmenger syndrome and receiving bosentan therapy. $\triangle \mathrm{PVRi}$ was demonstrated as the only independent predictor of clinical worsening $(\mathrm{HR}=0.973$; $95 \%$ confidence interval: $0.95-0.99 ; \mathrm{p}=0.01$ ), and $\Delta \mathrm{PVRi}<25 \%$, with $56 \%$ sensitivity and $100 \%$, specificity could predict clinical worsening. The area under the ROC curve was 0.773 (95\% confidence interval: $0.608-0.892$ ) [22].

\section{PULMONARY HYPERTENSION DUE TO LEFT HEART DISEASE (PH-2)}

Prognostic factors have also been identified in pulmonary hypertension due to left heart disease (PH-LHD), including subsets of patients with an LVEF $\geq 50 \%$ (PH-HFpEF) and LVEF $<50 \%$ (PH-HFrEF). Despite significantly higher DPG values in the PH-HFpEF compared to the PH-HFrEF group, the variable was not a significant predictor of survival. On the other hand, both groups had similar PCa values, but $\mathrm{PCa}<1.1 \mathrm{ml} / \mathrm{mmHg}$ in $\mathrm{PH}-\mathrm{HFpEF}$ [23] and $\mathrm{PCa}<2.15 \mathrm{ml} / \mathrm{mmHg}$ in PH-HFrEF [24] were established as significant predictors of survival.

The interpretation of DPG values appears more complex. An elevated DPG $\geq 7 \mathrm{mmHg}$ is associated with increased mortality in patients with PH due to LHD, but the correlation seems to be weak, and other factors e.g. levels of $\mathrm{N}$-terminal pro-brain natriuretic peptide (NT-proBNP) or NYHA class have better prognostic values [25]. On the other hand, available evidence suggests that DPG $\geq$ $7 \mathrm{mmHg}$ does not have a significant effect on survival in PH-LHD, but elevated PVR $>3 \mathrm{WU}$ and TPG $>9 \mathrm{mmHg}$ can be a predictor of death [26].

RHC is mandatory at all stages of the qualification process of heart failure patients for a heart transplant (HT). It should be performed not only prior to an adult patient being listed for cardiac transplantation but also repeated periodically until transplantation. The 2016 guidelines for HT recommend to adjust the assessment process to specific clinical circumstances [6]. The risk of death due to right heart failure after heart transplantation is significantly increased in some clinical situations: if PVR $>5$ WU or PVRI $>6$ WU.m ${ }^{2}$ (children), or TPG exceeding $16-20 \mathrm{mmHg}$; if PAPs $>60 \mathrm{mmHg}$ in combination with one of the former values or if PVR cannot be reduced to $<2.5$ after a vasodilator challenge without a drop in $\mathrm{SBP}<85 \mathrm{mmHg}$. Vasodilator testing should be performed in subjects with PAPs $>50 \mathrm{mmHg}$ and either TPG $>15 \mathrm{mmHg}$ 
or pulmonary PVR $>3 \mathrm{WU}$ (with SBP $>85 \mathrm{mmHg}$ ). The diagnosis of irreversible pulmonary hypertension should be suspected in patients with unsuccessful acute vasodilator testing and medical treatment failure [27].

A left ventricular assist device (LVAD) can significantly reduce PVR in heart transplant candidates. Regardless of preimplantation PVR: low ( $<5 \mathrm{WU}$ ) or high ( $\geq 5 \mathrm{WU})$, a 3-year survival after transplantation is similar between groups $(85.0 \%$ and $79.0 \%$, respectively), however posttransplant in-hospital mortality remains significantly increased among patients with the initially high PVR $(\mathrm{P}<0.05)[28]$. Even $\mathrm{PVR} \geq 3 \mathrm{WU}$ vs. PVR $<3$ WU places patients with HF and LVAD at higher risk of death (HR 1.55; $\mathrm{P}=0.026$ ), whereas elevated DPG is only associated with the development of RV failure (HR:3.30; $\mathrm{P}=0.004$ for $\mathrm{DPG} \geq 7$ versus DPG $<7$ ) [29].

There are other parameters, not included in the current HT guidelines, which can help evaluate patients before and after HT. One of them is relative pulmonary hypertension calculated from mean artery pressure (MAP) and PAPm (MAP/PAPm). Preoperative value $<3$ in transplant candidates $>60$ years of age is associated with lower survival rates after transplantation (HR 5.39; 95\% confidence interval: $1.64-17.74 ; \mathrm{p}=0.006$ ) [30]. Postoperative PAPm $>20 \mathrm{mmHg}$, compared to PAPm $\leq 20 \mathrm{mmHg}$, is linked to a significantly increased mortality rate within one year after transplantation $(11.5 \pm 0.7$ vs. $15.6 \pm 0.6$ years, $\mathrm{p}<0.001)$ [31].

Aortic stenosis is one of the most common valve diseases and its prevalence is expected to rise with an aging population. In some clinical situations RHC can help with patient evaluation and qualification for surgical treatment or transcatheter aortic valve implantation (TAVI). There is a significant association between $\mathrm{PH}$ and reduced survival after surgical aortic valve replacement $(\mathrm{p}=0.006)$ or TAVI (1-year mortality unadjusted: HR: 2.03; 95\% confidence interval: $1.07-3.85 ; \mathrm{p}=0.030$; after adjustment: HR: 1.95; 95\% confidence interval: $1.01-3.76 ; p=0.046$ ) [32]. Of all $\mathrm{PH}$ subgroups, $\mathrm{Cpc}-\mathrm{PH}$ remains the strongest predictor of death both for surgical (HR 4.39, 95\% confidence interval: $2.40-8.03 ; \mathrm{p}<0.001$ ) [33] and TAVI patients (adjusted HR: 3.28; 95\% confidence interval: $1.43-7.53 ; p=0.005$ at 1 year) [32]. In addition, among patients with severe aortic stenosis (AVA $<1 \mathrm{~cm}^{2}$ ) lack of postoperative reduction in PAPm $\geq 10 \mathrm{mmHg}$ is an independent predictor of mortality (HR: 0.93 ; 95\% confidence interval: $1.2-12.5$; $\mathrm{p}=0.048)$, whereas preoperatively elevated PAWP is a significant predictor of reduced PAPm (OR, 1.26; 95\% confidence interval: $1.13-1.41 ; \mathrm{p}<0.0001$ ) [34]. In aortic regurgitation, $\mathrm{PH}$ has been less studied.

The relationship between prognosis in mitral regurgitation and parameters related to pulmonary hypertension has been described in the literature, however, these are forecasts based mainly on PAPs values from echocardiographic measurements, which is beyond the scope of this study.

Rheumatic heart disease, especially mitral stenosis (MS) remains a major health problem in developing countries, and percutaneous balloon mitral valvotomy (PBMV) is a safe and effective procedure in symptomatic patients.
Baseline PVR> 1.81 WU has been shown to be an independent predictor of persistent elevation of RVSP $>50 \mathrm{mmHg}$ immediately after PBMV with $69 \%$ sensitivity and $86 \%$ specificity (95\% confidence interval: 64-95; $\mathrm{p}=0.002$; AUC $=0.79$ ) [35]. Furthermore, post-PBMV PAPm has been established as an independent predictor of all-cause mortality (per mmHg - HR: 1.045; 95\% confidence interval: $1.015-1.077 ; \mathrm{p}=0.003$ ) and mitral valve reintervention (per mmHg - HR: 1.055; 95\% confidence interval: $1.024-1.087 ; \mathrm{p}<0.001)$ [36].

\section{PULMONARY HYPERTENSION DUE TO LUNG DISEASES AND/OR HYPOXIA (PH-3)}

Although RHC is not recommended in conventional evaluation of $\mathrm{PH}-3$ patients, it may offer clues that help narrow the differential diagnosis and make therapeutic decisions regarding lung transplantation. $\mathrm{PH}$ was found to have a negative effect on survival after lung transplantation (LT) within 90 days of follow-up, compared to non- $\mathrm{PH}$ patients ( $p=0.043$ and $p=0.003$, respectively), but at one year after LT only pre-capillary $\mathrm{PH}$ versus post-capillary $\mathrm{PH}$ remained a negative prognostic factor $(\mathrm{p}=0.037$ and $\mathrm{p}=0.447$, respectively) [37]. In patients with end-stage lung disease awaiting LT, PAPm $\geq 30 \mathrm{mmHg}$, PAPd $\geq 20 \mathrm{mmHg}$ and PAPs $\geq 44 \mathrm{mmHg}$ are associated with worse prognosis with sensitivity $=70 \%, 70 \%, 73 \%$, specificity $=76 \%, 69 \%$, $72 \%$ and $A U C=0.67,0.68,0.72$, respectively [38]. Despite the correlation between mortality in patients awaiting LT and exacerbation of $\mathrm{PH}, \mathrm{PAH}$-approved drugs are not recommended due to inhibition of hypoxic pulmonary vasoconstriction [4].

\section{CHRONIC THROMBOEMBOLIC PULMONARY HYPERTENSION (PH-4)}

Not only direct RHC-derived measurements can be used to predict outcome in $\mathrm{PH}$ patients. Evidence shows that analysis of pulmonary artery occlusion pressure waveform might identify CTEPH patients with persistent $\mathrm{PH}$ after pulmonary thromboendarterectomy (PTE), which contributes to poor outcome. Pulmonary vascular resistance can be divided into large arterial (upstream, Rup) and small arterial plus venous (downstream) components (Fig 3). Lower Rup can be seen in patients with CTEPH with small vessel disease and embolic material so that it makes it impossible to perform an effective PTE. Patients with Rup $<60 \%$ seem to be at the highest risk of persistent $\mathrm{PH}$ after PTE [39]. Different cut-off points may influence the sensitivity and specificity of the Rup in distinguishing operable from inoperable CTEPH. The cut-off point of 79.3\% gives a $100 \%$ sensitivity and $57.1 \%$ specificity, whereas the cut-off value of $83.8 \%$ decreases sensitivity to $83.3 \%$ but specificity is increased to $71.4 \%$ [40].

The level of preoperative PVR, with a threshold $>800$ dyn.sec.cm-5, was found to be a risk factor for increased mortality in patients after PTE, with sensitivity and specificity of $77 \%$ and $60 \%$, respectively [41]. PAPm $\geq 38 \mathrm{mmHg}$ 
and PVR $\geq 425$ dyn.sec.cm-5 were predictors of poor outcome at 3-6 months post PTE [42].

Recent years have seen major advances in the CTEPH treatment. Balloon pulmonary angioplasty (BPA) has become a very useful alternative and complementary therapy to PTE, especially in inoperable patients with distal lesions. It is very important because at the moment of CTEPH diagnosis, almost $40 \%$ patients are considered inoperable [43]. In the biggest Japan BPA registry after a series of BPA procedures PAPm decreased from $43.2 \pm 11.0$ to $22.5 \pm 5.4 \mathrm{mmHg}$ [44], whereas in Polish patients with residual $\mathrm{PH}$ after $\mathrm{PTE}$, a series of $\mathrm{BAP}$ reduced $\mathrm{PAPm}$ from $44.7 \pm 6.4$ to $30.8 \pm 7.5 \mathrm{~mm} \mathrm{Hg}(31 \%$ decline; $\mathrm{p}<0.001)$ [45]. Substantial evidence shows that several RHC-derived measurements can be helpful in patient assessment before and after BPA. In multivariate analysis, PAPd at baseline was found to be an independent predictor of residual $\mathrm{PH}$ (PAPm $>30 \mathrm{mmHg}$ at follow-up) after BPA (OR: 2.04; 95\% confidence interval: $1.06-5.76 ; \mathrm{p}=0.029)$ [46] and a relative increase in $\mathrm{SvO} 2>125.4 \%$ over the baseline value significantly correlated with increased eGFR one year after BPA, with $100 \%$ specificity and $24.1 \%$ sensitivity [47].

It is essential to bear in mind that there are several potential risks related to the BPA procedure, with reperfusion pulmonary injury (RPI) being most important. Post-BPA pulmonary arterial pressure distal $(\mathrm{Pd})$ to the site of stenosis is associated with RPI occurrence (OR: 1.139, 95\% confidence interval: $1.053-1.231, \mathrm{p}=0.001$ ) and post-BPA Pd $>19.5$ $\mathrm{mmHg}$ can predict RPI with $79.6 \%$ sensitivity and $75.4 \%$ specificity, whereas the area under ROC curve is 0.814 [48].

\section{PULMONARY HYPERTENSION WITH UNCLEAR} AND/OR MULTIFACTORIAL MECHANISMS (PH-5) $\mathrm{PH}-5$ is a heterogeneous group of diseases with unclear or multifactorial mechanisms, requiring an individual approach to patients, for whom no universal treatment is available (Fig. 4) [4]. This category includes $\mathrm{PH}$ associated with sickle cell disease (SCD), where average life expectancy is 25.6 months, whereas a 119 -month survival of $70 \%$ has been reported in patients with SCD without $\mathrm{PH}$. RHC-derived measurements that affect outcome include PAPm, where each increase of $10 \mathrm{mmHg}$ is associated with an approximately 2 -fold increase in the rate of death [49], and TPG $\geq 12 \mathrm{mmHg}$ is deemed to be an independent predictor of increased mortality [50].

\section{CONCLUSIONS}

Despite the availability of a wide range of non-invasive diagnostic tests RHC remains the gold standard for assessing pulmonary artery pressure. RHC-derived parameters are useful not only for $\mathrm{PH}$ diagnosis but also for prognostic purposes in numerous $\mathrm{PH}$ subtypes, facilitating the decision-making process. Although they are not included in the current ESC guidelines, they may be extremely useful in everyday practice for evaluation of a heterogeneous group of patients with $\mathrm{PH}$. Comprehensive $\mathrm{PH}$ patient assessment is the cornerstone of individualized care with a significantly better outcome.

\section{REFERENCES}

1. Nossaman BD, Scruggs BA, Nossaman VE, Murthy SN, Kadowitz PJ. History of right heart catheterization: 100 years of experimentation and methodology development. Cardiol Rev. 2010;18(2):94-101. doi:10.1097/CRD.0b013e3181ceff67

2. Callan $P$, Clark AL. Right heart catheterisation: indications and interpretation. Heart. 2016;102(2):147-157. doi:10.1136/ heartjnl-2015-307786

3. Kopeć $G$, Kurzyna M, Mroczek E, et al. Characterization of patients with pulmonary arterial hypertension: Data from the Polish Registry of Pulmonary Hypertension (BNP-PL). JClin Med. 2020;9(1):173. Published 2020 Jan 8. doi:10.3390/jcm9010173

4. Galiè N, Humbert M, Vachiery JL, et al. 2015 ESC/ERS Guidelines for the diagnosis and treatment of pulmonary hypertension. Rev Esp Cardiol (Engl Ed). 2016;69(2):177. doi:10.1016/j.rec.2016.01.002

5. Callan P, Clark AL. Right heart catheterisation: indications and interpretation. Heart. 2016;102(2):147-157. doi:10.1136/ heartjnl-2015-307786

6. Mehra MR, Canter CE, Hannan MM, et al. The 2016 International Society for Heart Lung Transplantation listing criteria for heart transplantation: A 10-year update. J Heart Lung Transplant. 2016;35(1):1-23. doi:10.1016/j.healun.2015.10.023

7. Simonneau G, Montani D, Celermajer DS, etal. Haemodynamic definitions and updated clinical classification of pulmonary hypertension. Eur Respir J. 2019;53(1):1801913. doi:10.1183/13993003.01913-2018

8. Suzuki A, Taniguchi $H$, Watanabe $N$, et al. Significance of pulmonary arterial pressure as a prognostic indicator in lung-dominant connective tissue disease. PLoS One. 2014;9(9):e108339. doi:10.1371/journal. pone.0108339

9. Kimura M, Taniguchi H, Kondoh Y, et al. Pulmonary hypertension as a prognostic indicator at the initial evaluation in idiopathic pulmonary fibrosis. Respiration. 2013;85(6):456-463. doi:10.1159/000345221

10. Maron BA, Hess E, Maddox TM, et al. Association of Borderline Pulmonary hypertension with mortality and hospitalization in a large patient cohort: insights from the veterans affairs clinical assessment, reporting, and tracking program. Circulation. 2016;133(13):1240-1248. doi:10.1161/CIRCULATIONAHA.115.020207

11. Weatherald J, Boucly A, Chemla D, et al. Prognostic value of followup hemodynamic variables after initial management in pulmonary arterial Hypertension. Circulation. 2018;137(7):693-704. doi:10.1161/ CIRCULATIONAHA.117.029254

12. van Wolferen SA, Marcus JT, Boonstra A, et al. Prognostic value of right ventricular mass, volume, and function in idiopathic pulmonary arterial hypertension. Eur Heart J. 2007;28(10):1250-1257. doi:10.1093/ eurhearti/eh/477

13. Mazimba S, Mejia-Lopez E, Black G, et al. Diastolic pulmonary gradient predicts outcomes in group 1 pulmonary hypertension (analysis of the NIH primary pulmonary hypertension registry). Respir Med. 2016;119:81-86. doi:10.1016/j.rmed.2016.08.024

14. Farber HW, Miller DP, Poms AD, et al. Five-Year outcomes of patients enrolled in the REVEAL Registry. Chest. 2015;148(4):1043-1054. doi:10.1378/chest.15-0300

15. Benza RL, Gomberg-Maitland M, Miller DP, et al. The REVEAL Registry risk score calculator in patients newly diagnosed with pulmonary arterial hypertension. Chest. 2012;141(2):354-362. doi:10.1378/chest.11-0676 
16. Mukerjee D, St George D, Coleiro B, et al. Prevalence and outcome in systemic sclerosis associated pulmonary arterial hypertension: application of a registry approach. Ann Rheum Dis. 2003;62(11):10881093. doi:10.1136/ard.62.11.1088

17. Chung L, Farber HW, Benza R, et al. Unique predictors of mortality in patients with pulmonary arterial hypertension associated with systemic sclerosis in the REVEAL registry. Chest. 2014;146(6):1494-1504. doi:10.1378/chest.13-3014

18. Campo A, Mathai SC, Le Pavec J, et al. Hemodynamic predictors of survival in scleroderma-related pulmonary arterial hypertension. Am J Respir Crit Care Med. 2010;182(2):252-260. doi:10.1164/rccm.200912-18200C

19. Krowka MJ, PlevakDJ, Findlay JY, Rosen CB, Wiesner RH, Krom RA. Pulmonary hemodynamics and perioperative cardiopulmonary-related mortality in patients with portopulmonary hypertension undergoing liver transplantation. Liver Transpl. 2000;6(4):443-450. doi:10.1053/jlts.2000.6356

20. Cheng XL, Liu ZH, Gu Q, et al. Prognostic value of pulmonary artery compliance in patients with pulmonary arterial hypertension associated with adult congenital heart disease. Int Heart J. 2017;58(5):731-738. doi:10.1536/ihj.16-449

21. Mahapatra S, Nishimura RA, Sorajja P, Cha S, McGoon MD. Relationship of pulmonary arterial capacitance and mortality in idiopathic pulmonary arterial hypertension. J Am Coll Cardiol. 2006;47(4):799-803. doi:10.1016/j.jacc.2005.09.054

22. D'Alto M, Romeo E, Argiento P, et al. Pulmonary vasoreactivity predicts longterm outcome in patients with Eisenmenger syndrome receiving bosentan therapy. Heart. 2010;96(18):1475-1479. doi:10.1136/hrt.2010.199661

23. Al-Naamani N, Preston IR, Paulus JK, Hill NS, Roberts KE. Pulmonary Arterial Capacitance Is an Important Predictor of Mortality in Heart Failure With a Preserved Ejection Fraction. JACC Heart Fail. 2015;3(6):467-474. doi:10.1016/j.jchf.2015.01.013

24. Pellegrini P, Rossi A, Pasotti $M$, et al. Prognostic relevance of pulmonary arterial compliance in patients with chronic heart failure. Chest. 2014;145(5):1064-1070. doi:10.1378/chest.13-1510

25. Yamabe S, Dohi Y, Fujisaki S, et al. Prognostic factors for survival in pulmonary hypertension due to left heart disease. Circ J. 2016;80(1):243-249. doi:10.1253/circj.CJ-15-0708

26. Tampakakis E, Leary PJ, Selby VN, et al. The diastolic pulmonary gradient does not predict survival in patients with pulmonary hypertension due to left heart disease. JACC Heart Fail. 2015;3(1):9-16. doi:10.1016/j. jchf.2014.07.010

27. Mehra MR, Kobashigawa J, Starling R, et al. Listing criteria for heart transplantation: International Society for Heart and Lung Transplantation guidelines for the care of cardiac transplant candidates -2006. J Heart Lung Transplant. 2006;25(9):1024-1042. doi:10.1016/j. healun.2006.06.008

28. Tsukashita M, Takayama $H$, Takeda $K$, et al. Effect of pulmonary vascular resistance before left ventricular assist device implantation on shortand long-term post-transplant survival. J Thorac Cardiovasc Surg. 2015;150(5):1352-1361.e13612. doi:10.1016/j.jtcvs.2015.07.012

29. Alnsasra H, Asleh $R$, Schettle SD, et al. Diastolic pulmonary gradient as a predictor of right ventricular failure after left ventricular assist device implantation. J Am Heart Assoc. 2019;8(16):e012073. doi:10.1161/ JAHA.119.012073

30. Bianco JC, Mc Loughlin S, Denault AY, Marenchino RG, Rojas Jl, Bonofiglio FC. Heart transplantation in patients $>60$ years: Importance of relative pulmonary hypertension and right ventricular failure on midterm survival. J Cardiothorac Vasc Anesth. 2018;32(1):32-40. doi:10.1053/j. jvca.2017.09.017
31. Gude E, Simonsen S, Geiran OR, et al. Pulmonary hypertension in heart transplantation: discrepant prognostic impact of pre-operative compared with 1-year post-operative right heart hemodynamics. J Heart Lung Transplant. 2010;29(2):216-223. doi:10.1016/j.healun.2009.08.021

32. O'Sullivan CJ, Wenaweser P, Ceylan 0, et al. Effect of pulmonary hypertension hemodynamic presentation on clinical outcomes in patients with severe symptomatic aortic valve stenosis undergoing transcatheter aortic valve implantation: Insights from the new proposed pulmonary hypertension classification. Circ Cardiovasc Interv. 2015;8(7):e002358. doi:10.1161/CIRCINTERVENTIONS.114.002358

33. Weber L, Rickli H, Haager PK, et al. Haemodynamic mechanisms and long-term prognostic impact of pulmonary hypertension in patients with severe aortic stenosis undergoing valve replacement. Eur J Heart Fail. 2019;21(2):172-181. doi:10.1002/ejhf.1322

34. Cam A, Goel SS, Agarwal S, et al. Prognostic implications of pulmonary hypertension in patients with severe aortic stenosis. JThorac Cardiovasc Surg. 2011;142(4):800-808. doi:10.1016/j.jtcvs.2010.12.024

35. Elmaghawry LM, El-Dosouky II, Kandil NT, Sayyid-Ahmad AMS. Pulmonary vascular resistance and proper timing of percutaneous balloon mitral valvotomy. Int J Cardiovasc Imaging. 2018;34(4):523529. doi:10.1007/s10554-017-1255-3

36. Jorge $E$, Pan M, Baptista $R$, et al. Predictors of very late events after percutaneous mitral valvuloplasty in patients with mitral stenosis. Am J Cardiol. 2016;117(12):1978-1984. doi:10.1016/j.amjcard.2016.03.051

37. Andersen KH, Schultz HH, Nyholm B, Iversen MP, Gustafsson F, Carlsen J. Pulmonary hypertension as a risk factor of mortality after lung transplantation.Clin Transplant. 2016;30(4):357-364. doi:10.1111/ctr.12692

38. Nowak J, Hudzik B, Przybyłowski P, et al. Prognostic value of mean, diastolic, and systolic pulmonary artery pressure in patients with endstage lung disease referred for lung transplantation. Transplant Proc. 2018;50(7):2048-2052. doi:10.1016/j.transproceed.2018.02.152

39. Kim NH, Fesler P, Channick RN, et al. Preoperative partitioning of pulmonary vascular resistance correlates with early outcome after thromboendarterectomy for chronic thromboembolic pulmonary hypertension. Circulation. 2004;109(1):18-22. doi:10.1161/01. CIR.0000111841.28126.D4

40. Toshner M, Suntharalingam J, Fesler $P$, et al. Occlusion pressure analysis role in partitioning of pulmonary vascular resistance in CTEPH. Eur Respir J. 2012;40(3):612-617. doi:10.1183/09031936.00134111

41. Tromeur $C$, Jaïs $X$, Mercier 0 , et al. Factors predicting outcome after pulmonary endarterectomy. PLoS One. 2018;13(6):e0198198. doi:10.1371/journal.pone.0198198

42. Cannon JE, Su L, Kiely DG, et al. Dynamic risk stratification of patient long-term outcome after pulmonary endarterectomy: Results from the United Kingdom national cohort. Circulation. 2016;133(18):1761-1771. doi:10.1161/CIRCULATIONAHA.115.019470

43. Pepke-Zaba J, Delcroix M, Lang I, et al. Chronic thromboembolic pulmonary hypertension (CTEPH): Results from an international prospective registry. Circulation. 2011;124(18):1973-1981. doi:10.1161/CIRCULATIONAHA.110.015008

44. Ogawa A, Satoh T, Fukuda T, et al. Balloon pulmonary angioplasty for chronic thromboembolic pulmonary hypertension: Results of a multicenter registry. Circ Cardiovasc Qual Outcomes. 2017;10(11):e004029. doi:10.1161/CIRCOUTCOMES.117.004029

45. Araszkiewicz A, Darocha S, Pietrasik A, et al. Balloon pulmonary angioplasty for the treatment of residual or recurrent pulmonary hypertension after pulmonary endarterectomy. Int J Cardiol. 2019;278:232-237. doi:10.1016/j.ijcard.2018.10.066 
46. Tsuji A, Ogo T, Ueda J, et al. Predictors of residual pulmonary hypertension after balloon pulmonary angioplasty in patients with chronic thromboembolic pulmonary hypertension. Int J Cardiol. 2017;226:118-120. doi:10.1016/j.jicard.2016.09.132

47. Isobe $S$, Itabashi Y, Kawakami T, et al. Increasing mixed venous oxygen saturation is a predictor of improved renal function after balloon pulmonary angioplasty in patients with chronic thromboembolic pulmonary hypertension. Heart Vessels. 2019;34(4):688-697. doi:10.1007/s00380-018-1284-4

48. Kinutani $H$, Shinke T, Nakayama K, et al. High perfusion pressure as a predictor of reperfusion pulmonary injury after balloon pulmonary angioplasty for chronic thromboembolic pulmonary hypertension. Int J Cardiol Heart Vasc. 2015;11:1-6. Published 2015 Nov 26. doi:10.1016/j. ijcha.2015.11.006

49. Castro 0, Hoque M, Brown BD. Pulmonary hypertension in sickle cell disease: cardiac catheterization results and survival. Blood. 2003;101(4):1257-1261. doi:10.1182/blood-2002-03-0948

50. Nguyen KL, Tian X, Alam S, et al. Elevated transpulmonary gradient and cardiac magnetic resonance-derived right ventricular remodeling predict poor outcomes in sickle cell disease. Haematologica. 2016;101(2):e40-e43. doi:10.3324/haematol.2015.125229

\section{ORCID and contributionship}

Karolina Barańska-Pawełczak - 0000-0003-4846-5598 A-F

Celina Wojciechowska - 0000-0003-3700-8439 ${ }^{\text {E-F }}$

Wojciech Jacheć - 0000-0002-1091-9788 A,E-F

\section{Conflict of interest}

The Authors declare no conflict of interest.

\section{CORRESPONDING AUTHOR}

Karolina Barańska-Pawełczak

Department of Cardiology,

Specilistic Hospital in Zabrze

M. Curie-Skłodowskiej st. 9, 41-800 Zabrze, Poland

e-mail:km.baranska@gmail.com

Received: 24.10 .2020

Accepted:12.02.2021

A - Work concept and design, B - Data collection and analysis, C - Responsibility for statistical analysis,

D - Writing the article, $\mathbf{E}$ - Critical review, $\mathbf{F}$ - Final approval of the article 